\title{
The Role of Verbal Aggression in Cyberbullying Perpetration and Victimization by Middle School Students
}

\author{
Jen Eden ${ }^{1, *}$ and Anthony J. Roberto ${ }^{2}$ \\ 1 School of Communication and the Arts, Marist College, Poughkeepsie, NY 12538, USA \\ 2 Hugh Downs School of Human Communication, Arizona State University, Tempe, AZ 85287, USA; \\ Anthony.Roberto@asu.edu \\ * Correspondence: Jen.eden@marist.edu; Tel.: +1-8455752299
}

check for

updates

Citation: Eden, J.; Roberto, A.J. The

Role of Verbal Aggression in

Cyberbullying Perpetration and

Victimization by Middle School

Students. Future Internet 2021, 13, 223.

https://doi.org/10.3390/fi13090223

Academic Editors:

María Tomé-Fernández,

Andrea Guazzini and

Annalaura Nocentini

Received: 31 July 2021

Accepted: 27 August 2021

Published: 30 August 2021

Publisher's Note: MDPI stays neutral with regard to jurisdictional claims in published maps and institutional affiliations.

Copyright: (c) 2021 by the authors. Licensee MDPI, Basel, Switzerland. This article is an open access article distributed under the terms and conditions of the Creative Commons Attribution (CC BY) license (https:/ / creativecommons.org/licenses/by/ $4.0 /)$.

\begin{abstract}
This manuscript examined the role trait verbal aggression plays in cyberbullying victimization and perpetration in adolescence. More than 400 middle school students $(46.8 \%$ males and $52.2 \%$ females) completed a questionnaire on trait verbal aggression and their history of cyberbullying perpetration and victimization. Linear regression analyses revealed that trait verbal aggression was a statistically significant predictor of both cyberbullying perpetration and victimization, that cyberbullying perpetration and cyberbullying victimization are related, and that cyberbullying perpetration appears to increase with age, while cyberbullying victimization does not. Ideas and implications for future applications of verbal aggression and cyberbullying are discussed.
\end{abstract}

Keywords: cyberbullying; perpetration; skills deficiency; verbal aggression; victimization

\section{Introduction}

When the Pew Internet and American Life Project first started keeping track in 2005, only five percent of Americans used social media; however, that number has jumped to over $72 \%$ in 2021 [1]. Alarmingly, teen and young adult technology use continues to increase with "nearly all U.S. teens (95\%) reporting access to a smartphone" (para 1) [2] and European children's internet use more than doubled since 2010 [3]. Although these new technologies have the potential to impact human communication positively, they can also be exploited and used to intimidate or hurt others. In fact, as access to technology increases, so do the risks of online perpetration and victimization [4].

Cyberbullying is defined as "the deliberate and repeated misuse of communication technology by an individual or group to threaten or harm others" (p. 201) [5]. Teens, in particular, have reported that they experience cyberbullying because of their pervasive technology use [6]. In recent international studies, approximately $17 \%$ of U.S. students had been cyberbullied through communication technology [7], while less than $10 \%$ of European children experienced the same phenomenon [3], though estimates may vary with specificity of measurement. On the other hand, cyberbullying perpetration occurs most frequently in middle school (33\%), and more than $50 \%$ of students report witnessing cyberbullying as a bystander [8]. Cyberbullies threaten to hurt their victim physically or send their victim messages intended to inflict psychological pain. Common types of messages designed to produce psychological harm include those that that insult, attack, embarrass, exclude, spread rumors about, or harm the relationships of the cyberbullying victim. Unfortunately, examples of teens being cyberbullied and taking their own lives are numerous and occur frequently all over the world. In just the last decade, the news has brought attention to several tragic instances of cyberbullying. Megan Meier, for instance, committed suicide after her friend's mother posed as a teenager to cyberbully Megan [9]. Rehtaeh Parson was a Canadian teen who took her own life after pictures of her were dispersed online [10]. Marian Hernández Rojas was a young girl who committed suicide after being bullied online [11], and Channing Smith was a 16-year old from Tennessee who 
committed suicide after classmates outed him online [12]. These stories, to name just a few, shed light on the extremely negative consequences of cyberbullying and highlight the urgency and importance of studying the topic further.

While many people may experience cyberbullying, scholars have found that middle school students may be the most vulnerable population $[7,13,14]$, as it is during middle school that cyberbullying perpetration often takes hold, with rates as low as $3 \%$ in sixth grade, growing to $19 \%$ of eight graders [15]. In fact, a recent study found victimization estimates in middle school as high as $84 \%$ [16]. Based on previous research linking trait verbal aggression, age $[17,18]$, sex $[13,14]$, previous cyberbullying victimization, and/or perpetration experience $[14,17-21]$ to future cyberbullying victimization and perpetration, we aimed to examine the impact these variables have on cyberbullying for young adults.

\subsection{Verbal Aggression}

Trait verbal aggression is defined as "attacking the self-concept of another person instead of, or in addition to, the person's position on a topic of communication" (p. 61) [22]. Examples of verbally aggressive messages include attacking a person's character, competence, physical appearance, background, or personality, and other behaviors such as threats, yelling, profanity, rejection, and disconfirmation [22]. The argumentative skills deficiency theory suggests that verbal aggression can lead to physical aggression when more constructive communication skills for dealing with a conflict are lacking [23].

A large body of literature concerning skills deficiency exists for both adult and adolescent populations. In adults, Infante, Chandler, and Rudd [24] found that husbands and wives in violent marriages were significantly higher in trait verbal aggressiveness than husbands and wives in nonviolent marriages. Further, Infante, Sabourin, Rudd, and Shannon [25] and Sabourin, Infante, and Rudd [26] found that husbands and wives in nonviolent disputes engaged in significantly fewer verbally aggressive acts than husband and wives in violent disputes. Infante et al. conclude that "a norm of reciprocity operates for verbal aggression, i.e., verbal aggression begets the same" (p. 364) [25]. In the realm of parent-child communication, Anthony et al. [27] and Anthony et al. [28] found that parents who were high in trait verbal aggression were more likely to use corporal punishment than parents who were low in trait verbal aggression. On the other hand, Savage and Tokunaga [20] propose that perhaps antisocial behaviors such as cyberbullying require perpetrators to have some degree of competence in their social skills in order to exact control over their victims.

In adolescents, Anthony et al. [29] found that boys high in trait verbal aggressiveness were significantly more likely to have been suspended for fighting than boys low in trait verbal aggressiveness. Likewise, Savage and Tokunaga [20] found that trait verbal aggressiveness was related to cyberbullying perpetration. Finally, Anthony et al. [17] found that trait verbal aggression was a significant predictor of cyberbullying in high school seniors. Given the previous research on trait verbal aggression and skills deficiency, the reciprocal nature of verbal aggression, and the relationship trait verbal aggression has with cyberbullying victimization and perpetration [15,30-32], we propose the following hypotheses:

Hypothesis 1. Trait verbal aggression will be positively related to cyberbullying perpetration and victimization in adolescent middle school students.

Hypothesis 2. Cyberbullying victimization and cyberbullying perpetration will be positively related to one another.

\subsection{Age}

Unfortunately, cyberbullying has become prevalent among school-age children [33]. In a recent nationally representative survey of teenagers, the Pew Internet and American Life Project found that approximately $60 \%$ of teens aged $12-17$ years old have personally expe- 
rienced abusive online behaviors [34]. Precisely identifying the age at which cyberbullying most frequently occurs matters when designing the most efficacious anti-cyberbullying interventions. However, assessing the relationship between age and cyberbullying has proven difficult because there are many external factors. Estimates of victimization and perpetration vary widely depending on demographic (sexuality, gender identity, disability, ethnicity [35]), individual (e.g., previous experiences with victimization and technology use), family, peer, and school factors [36]. Estimates also fluctuate based on the way researchers measured those experiences; in some studies, scholars measured precise age; others measured age ranges, and some just recorded year in school [37]. In other cases, there is imprecision in measurement related to experiences of cyberbullying; in some cases, measuring experiences within a specific time period such as "in the last week" and in others asking about experiences over the participant's entire lifespan [37]. Finally, estimates differ depending on whether researchers assess victimization, perpetration, or bully-victims $[15,17]$. While there have been mixed results on the precise impact of age, a growing body of evidence shows that cyberbullying is greatest in middle school, raising after fifth grade and peaking in eighth grade [38,39]. However, many scholars have found that instances of cyberbullying perpetration in middle school continue to increase if not met with impactful anti-cyberbullying campaigns [15,40]. In fact, some scholars have found that cyberbullying victimization post middle school has been reported at as high as $56 \%$, calling for researchers to continue examining this experience across the age spectrum [41]. Taken together, the preponderance of evidence seems to suggest that, in middle school, those who are older will be more likely to both perpetrate and be victimized by cyberbullying. Therefore, we propose the following hypothesis:

Hypothesis 3. There is a positive relationship between age and both cyberbullying perpetration and cyberbullying victimization.

\subsection{Sex}

Studies examining sex differences in cyberbullying perpetration and victimization have found inconsistent results as well. Kowalski and Limber [14] found that girls were more likely to be victims than boys. Anthony et al. [17] found that the majority of the perpetrators in their study of high school students were female (63\%), which is in line with previous research indicating that girls are more likely to use indirect forms of aggression, whereas boys are more likely to use physical forms of aggression [42]. In the realm of cyberbullying, Sourander et al. [43] found that women were more likely to be victims, and men were more likely to be perpetrators, though Ybarra and Mitchell [44] found no sex differences in rates of victimization and perpetration. Similarly, Brody and Vangelisti [45] found no sex differences in rates of victimization by cyberbullying strategy but did find differences in terms of topics. Women were more likely than men to experience cyberbullying related to sexual experiences, whereas men were more likely to be targeted about their sexual orientation [45]. Finally, in a recent study, publication year moderated sex differences in cyberbullying frequency rates such that more recent cyberbullying publications found fewer sex differences [46]. Given the inconsistencies previously reported on the impact of sex on cyberbullying perpetrators and victims, we propose the following research question:

RQ1: What is the relationship between victims and perpetrators of cyberbullying and sex?

\section{Materials and Methods}

\subsection{Participants}

This study included a convenience sample of students from a middle school located in a large southwestern U.S. city. Seventy-five percent of students' primary caregivers provided consent for their children to take part in the study, and $69 \%$ of students were present on the day data collection took place. Four hundred and forty students in the 6 th grade $(n=133)$, 7 th grade $(n=156)$, and 8 th grade $(n=151)$ took part in the study. 
The sample included $206(46.8 \%)$ males and $234(52.2 \%)$ females. The mean age was 12.58 $(\mathrm{SD}=1.02$; range $=10$ - to 15 -years old). The sample was multi-ethnic with $58 \%$ White, $39 \%$ Latinx, 37\%, American Indian, 35\% Black, 34\% Asian, and 41\% "other" (note: the total for race is more than $100 \%$ because participants were asked to check all that apply). All students enrolled at this school at the time of data collection were eligible to participate because we were interested in capturing the widest range of cyberbullying experiences. One small group of students who took classes exclusively in a special needs education room were excluded from our analysis because inclusion would have made their responses identifiable in the larger analysis.

\subsection{Procedures}

Data were collected as part of a larger study to assess the effects of an intervention to promote social networking safety and prevent future cyberbullying [15]. In addition to measuring the dependent variables for that study, we also took the opportunity to measure past cyberbullying victimization and perpetration, trait verbal aggression [22], as well as sex and age. All surveys were administered during a regularly scheduled class period. The survey was deemed appropriate for students of this age based on the authors' past experiences working with this age group, results of the Flesch-Kincaid readability test, and discussions with teachers and administrators who reviewed drafts of the survey while it was being developed. Data collection took place toward the end of the school year in May 2009 for the students (i.e., 6th, 7th, or 8th grade) who participated [15]. Additionally, because of the sampling method, care should be taken in making generalizations beyond the scope of this study.

\subsection{Instrumentation}

Cyberbullying perpetration and victimization. The measures for cyberbullying perpetration and victimization were developed by the authors after an extensive review of the cyberbullying literature [5]. This measure is similar to measures of traditional bullying that are often used with this age group [47], and a similar measure has been successfully used with young adults to measure cyberbullying perpetration and victimization during high school [17]. For this study, cyberbullying perpetration was measured with a dichotomous ("yes/no") item, followed by a continuous contingency item for those who answered "yes". Before answering these questions, students received a brief set of general instructions and some examples of the types of behaviors of interest. Then, students were asked, "During the current school year, did you ever use a cell phone or the Internet to send or post messages or images to hurt or embarrass someone else in an unfriendly way?" Students who answered affirmatively were also asked, "If 'yes', how many times did you do this during the current school year (for example, at different times, to different people, or for different reasons)?" Response categories for this contingency item ranged from "1" to "6 or more". Cyberbullying victimization was measured using identical procedures, except the focus was changed to determine if anyone else had ever behaved this way to them.

\subsection{Trait Verbal Aggression}

Trait verbal aggression was measured using five negatively worded items from Infante and Wigley's [22] verbal aggression scale (i.e., "When people are very stubborn, I use insults to make them more flexible", "When people behave badly, I insult them in order to get them to behave better", "When people will not budge on an important issue, I get angry and say nasty things to them", "When people insult me, I like to really tell them off", and "I like making fun of people who do things which are very stupid in order to make them smarter"). The verbal aggression scale was adapted for adolescent populations by Anthony et al. [48]. Only negatively worded items were used based on results and recommendations made by Levine et al. [49]. Using a shorter version of the original scale is also common (e.g., Anthony et al. [48] ended up with eight items; Infante and Gorden [50] used five items; etc.). In the present study, Cronbach's alpha for internal consistency of the five-item trait 
verbal aggression measure was $\alpha=0.81$. To verify the latent factor structure for our verbal aggression measure, a principal axis factor analysis was conducted with varimax rotation. Prior to conducting this analysis, the correlation matrix was examined to assure that correlations were above 0.30 , indicating that factor analysis is appropriate but below 0.80 (See Table 1 for correlation matrix among verbal aggression items). The determinant was 0.191; Bartlett's test of sphericity was significant; and the $\mathrm{KMO}=0.84$, providing additional evidence that factor analysis is appropriate, and there is no multicollinearity among these measure items. One factor was extracted which is confirmed by the Eigenvalue cutoff rule and by examining the scree plot.

Table 1. Spearman correlations among verbal aggression items.

\begin{tabular}{lcccc}
\hline & $\mathbf{1}$ & $\mathbf{2}$ & $\mathbf{3}$ & $\mathbf{4}$ \\
\hline 1. VA1 & & & & \\
2. VA2 & $0.60^{*}$ & & & \\
3. VA3 & $0.50^{*}$ & $0.57^{*}$ & & \\
4. VA4 & $0.43^{*}$ & $0.46^{*}$ & $0.40^{*}$ & $0.40^{*}$ \\
5. VA5 & $0.46^{*}$ & $0.49^{*}$ & $0.48^{*}$ & \\
\hline${ }^{*} p<0.01$. & & & &
\end{tabular}

\subsection{Data Collection}

The project had approval from the primary investigator's institutional review board, and the research team followed the guidelines laid out by the Declaration of Helsinki. Participation in the study was voluntary, and informed consent was collected from students' primary caregivers prior to data collection. Student responses to the survey were anonymous; no identifying information was collected. Two multivariate regressions models were estimated, one estimating predictors of cyberbullying perpetration and one estimating predictors of cyberbullying victimization. All analyses were conducted using SPSS version 26.0; additional details about multivariate regression analyses are included below.

\section{Results}

\subsection{Descriptives}

As noted previously, these data were collected as part of a larger project. While we report frequencies for cyberbullying perpetration and victimization for this sample in another paper [15], we have not previously looked at the effects of verbal aggression on these variables for this sample, nor have we looked at the combined effects of verbal aggression, age, and sex on cyberbullying victimization and perpetration with this sample. With this in mind, students perpetrated cyberbullying less often $12 \%(n=50)$ than they were victims of cyberbullying $24 \%(n=100)$. For the full sample, the mean for cyberbullying perpetration was $0.28(\mathrm{SD}=1.08)$, and the mean for cyberbullying victimization was 0.59 $(\mathrm{SD}=1.38)$. However, if you look at just the perpetrators and just the victims, these means increase to $1.67(\mathrm{SD}=2.10)$ for perpetration and $2.52(\mathrm{SD}=1.81)$ for victimization. This suggests that those who are perpetrators or victims of cyberbullying tend to do or be so on multiple occasions. Participants' verbal aggression scores were relatively low $(\mathrm{M}=1.94$, $\mathrm{SD}=0.86$ ) overall. See Figures $1-3$ for frequency charts of verbal aggression, cyberbullying perpetration, and cyberbullying victimization. 


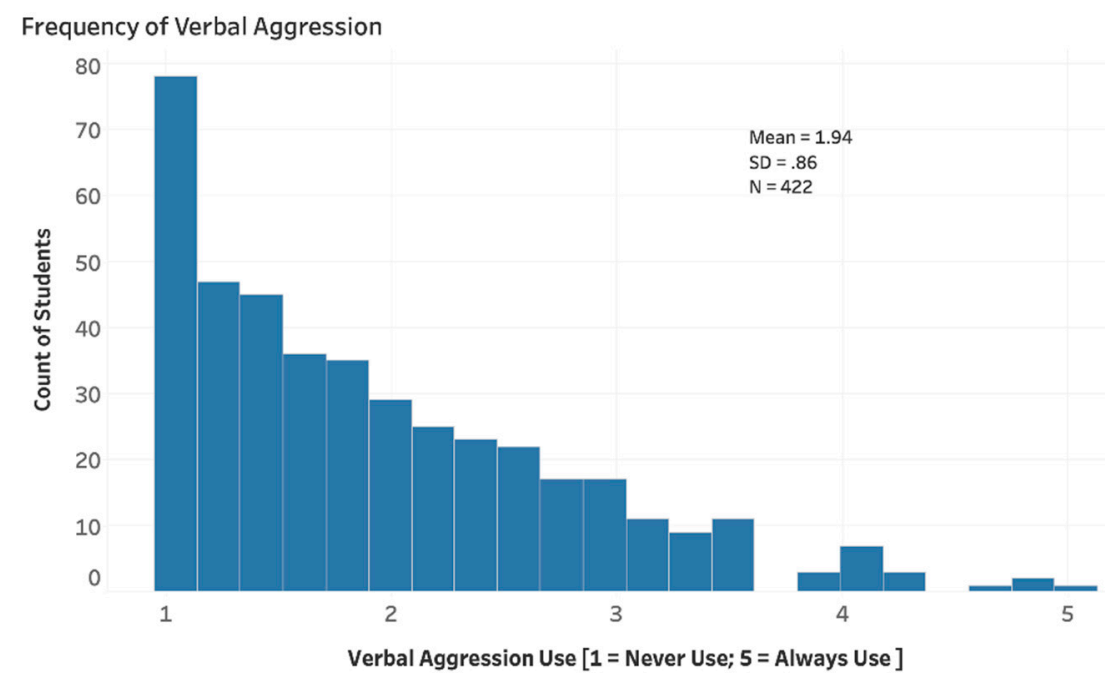

Figure 1. Frequency graph of verbal aggression.

Number of Cyberbully Perpetration Instances In The Last Year

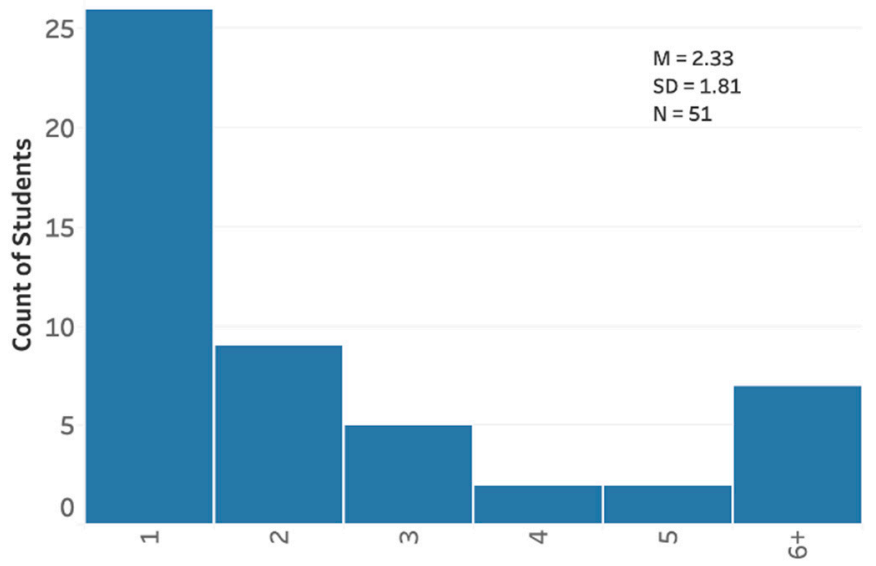

Figure 2. Frequency graph of cyberbullying perpetration.

Number of Cyberbully Victimization Instances In The Last Year

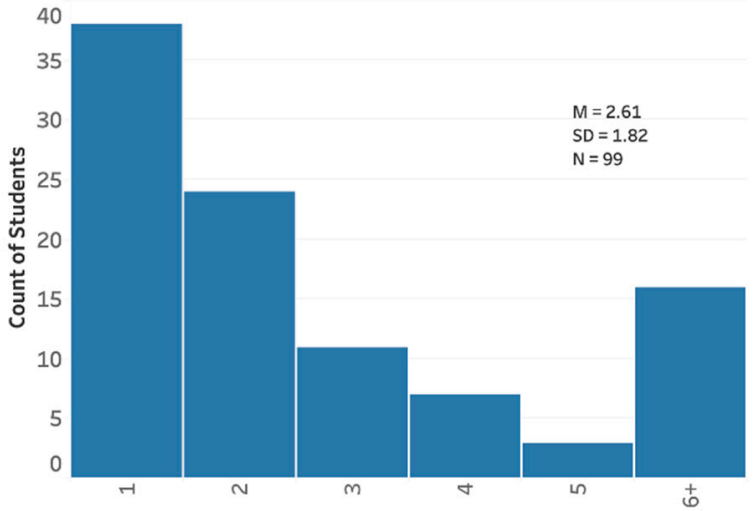

Figure 3. Frequency graph of cyberbullying victimization.

\subsection{Main Analyses}

The first regression model assessed predictors of cyberbullying victimization. Age, cyberbullying perpetration, verbal aggression, and sex (dummy coded: $0=$ male, $1=$ female to approximate a continuous variable) were included as predictors through the enter method with cyberbullying victimization as the criterion variable. To verify that the as- 
sumptions of linearity were met, a scatterplot was created to identify outliers and to verify the linear relationship among variables. The assumption of linearity was not violated. The independence assumption was not violated, Durbin-Watson statistic $=1.97$. To assess homoscedasticity, a scatterplot of the residuals was estimated. There is no obvious pattern, nor cone shape to the data. Additionally, correlations were examined (see Table 2 for Pearson correlations among variables), and collinearity diagnostics indicate an absence of multicollinearity, VIF = 1.0 for all predictors. Finally, Q-Q plots show normally distributed residuals and verify that the assumption of normality was not violated. The overall model was statistically significant, $F(4414)=13.28, p<0.001, R^{2}=0.12$, adjusted $R^{2}=0.11^{2}$, meaning the overall model accounted for approximately $11 \%$ of the variance in cyberbullying victimization. Sex $\beta=0.51, p<0.001, \mathrm{sr}^{2}=0.18$, cyberbullying perpetration $\beta=0.34$, $p<0.001, \mathrm{sr}^{2}=0.22$, and verbal aggression $\beta=0.23, p<0.05, \mathrm{sr}^{2}=0.14$ were statistically significant predictors of cyberbullying victimization. Results from an independent samples $t$-test indicate a statistically significant difference in sex for victimization, $t(423)=-3.37$, $p<0.001$, with females reporting higher levels of victimization $(M=0.80, S D=1.58)$ than males $(M=0.35, S D=1.07)$.

Table 2. Pearson correlations among variables.

\begin{tabular}{ccccc}
\hline & $\mathbf{1}$ & $\mathbf{2}$ & $\mathbf{3}$ & $\mathbf{4}$ \\
\hline 1. Age & & & & \\
2. Sex & -0.08 & & & \\
3. CB Victimization & 0.08 & $0.16^{*}$ & & \\
4. CB Perpetration & $0.15^{*}$ & 0.05 & $0.26^{*}$ & \\
5. Verbal Aggression & $0.16^{*}$ & $-0.21^{*}$ & $0.15^{*}$ & $0.19^{*}$ \\
\hline${ }^{*} p<0.01$. & & & &
\end{tabular}

A second regression model estimated which variables predicted cyberbullying perpetration. Again, age, cyberbullying victimization, verbal aggression, and sex (dummy coded: $0=$ male, $1=$ female, to approximate a continuous variable) were included as predictors through the enter method with cyberbullying perpetration as the criterion variable. Once again, assumptions of linear regression were assessed. A scatterplot was created to check for outliers and verify that the variables do indeed have a linear relationship with one another. The assumption of linearity was not violated. Next, the interdependence assumption was checked, and the Durbin-Watson statistic indicates that this assumption was also not violated $(\mathrm{D}-\mathrm{W}=2.04)$. A scatterplot of residuals was created to verify that the data are not conical in shape, and collinearity diagnostics $(\mathrm{VIF}=1.0)$ confirm that the assumption of homoscedasticity was not violated. Finally, Q-Q plots reveal that the residuals are normally distributed which means that the assumption of normality was not violated. The overall model was statistically significant, $\mathrm{F}(4414)=12.69, p<0.001, \mathrm{R}^{2}=0.11$, adjusted $\mathrm{R}^{2}=0.10$, meaning the overall model accounted for approximately $10 \%$ of the variance in cyberbullying perpetration. Age $\beta=0.11, p<0.05, \mathrm{sr}^{2}=0.12$, cyberbullying victimization $\beta=0.16, p<0.001, \mathrm{sr}^{2}=0.22$, and verbal aggression $\beta=0.17, p<0.01, \mathrm{sr}^{2}=0.14$ were statistically significant predictors of cyberbullying perpetration.

\section{Discussion}

This manuscript aimed to examine the role that trait verbal aggression plays in cyberbullying victimization and perpetration in middle school students. The current manuscript used linear regression to look at the combined effects of multiple variables simultaneously that have been typically studied independently from one another in a middle school sample $[19,44]$. Trait verbal aggression was a statistically significant predictor of both cyberbullying perpetration and cyberbullying victimization, uniquely explaining about $14 \%$ of the variance in both perpetration and victimization. Though these effects are relatively small [51] they are similar in size to verbal aggression effect sizes reported in several meta-analyses [52-54]; therefore, Hypothesis 1 was supported. Students who had higher scores on verbal aggression resorted to other types of aggressive behaviors, namely 
cyberbullying. This provides further evidence that the argumentative skills deficiency theory can be extended to help explain why individuals engage in perpetration as traditional bullies or in adolescence as cyberbullies. Further, results show that cyberbullying perpetration and cyberbullying victimization are related, supporting Hypothesis 2 . This finding falls in line with other typical forms of verbal aggression which have been shown to be reciprocal $[25,55]$. Additionally, the unique contributions of sex $(18 \%)$ and previous cyberbully perpetration (22\%) were small to moderate for victimization, while the unique contributions of age (11\%) and previous victimization $(16 \%)$ for perpetration were small. However, these effect size estimates are similar in size to estimates reported in recent meta-analyses of cyberbullying research [55-57].

We found partial support for Hypothesis 3. In the current study, cyberbullying perpetration appears to increase with age, while cyberbullying victimization does not. Notably, Anthony et al. [17] found that 35\% of their participants reported being a perpetrator of cyberbullying during the senior year of high school. Recent studies have found similar estimates of cyberbullying during high school [58-62], and, that outside of the COVID-19 pandemic school year where cyberbullying decreased $[63,64]$, cyberbullying perpetration increases through middle school and then stabilizes through high school [7,37,60,61,65-67]. These findings taken together suggest this upward trend continues beyond middle school, and that middle school and early high school may be the best time to intervene $[15,38-41,68]$. Results from Anthony et al. [17] which, amongst other things, studied the relationship between verbal aggression and cyberbullying perpetration in high school seniors, suggest that the relationship between verbal aggression and cyberbullying perpetration might grow even stronger over time (i.e., the relationship between these two variables appears to be even stronger in high school than it is in middle school). In fact, a recent meta-analysis of anti-cyberbullying interventions found that they were most effective in decreasing perpetration and aggression when they helped build concrete skills $[68,69]$. In tandem, these results highlight the importance of early prevention efforts when it comes to verbal aggression in general, and cyberbullying in particular, and provide additional evidence for argumentative skills deficiency theory $[69,70]$.

Currently, there is no clear picture regarding the relationship between sex and cyberbullying perpetration and victimization [61]. For example, several studies have found that neither boys nor girls were especially more likely to take on the role of cyberbullying perpetrator or victim $[17,38,61,71]$. On the other hand, Willard [72] reports that female students perpetrate a higher ratio of cyberbullying than male students while SchultzeKrumbholz, Hess, Pfetsch, and Scheithauer found that male students were most likely to experience cyber victimization [73]. Both Kowalski and Limber [14] and Roch, Elsayed, and Edwards [74] found that girls are more likely to be victims of cyberbullying than boys. To address our research question, we found that middle school girls in this study are significantly more likely to be victims of cyberbullying, but there were no sex differences for cyberbullying perpetration. One possibility is that some studies are looking at bivariate relationships between sex, cyberbullying perpetration, and cyberbullying victimization, while others are looking at the combined relationships between these two variables in conjunction with other theoretically and practically important variables (as we characterized in this study). Unfortunately, it seems there is still not yet enough research to say for sure one way or the other. Given all this, there is clearly a need for more research in this area in order to determine when and why sex and gender differences are likely to occur.

\section{Strengths and Limitations}

The primary strengths of this research are that it deals with a very important topic, includes a large sample, has strong measurement, and focuses on an important age group (i.e., middle school students) that is often very difficult to study. It also helps bring the field of communication to bear on an important new topic and increasingly common problem that adversely affects the lives of many adolescents and young adults. A key limitation is that it was conducted as part of a larger study, making it impossible for us to measure all the 
possible predictors of cyberbullying perpetration and victimization that might have been included if this was the sole focus of data collection. Thus, we chose to focus on one key communication variable (i.e., verbal aggression) that has been shown to be related to other types of aggressive behavior in this [29] and other age groups [25]. For example, based on previous research, Anthony et al. [17] examined the relationships between numerous variables previously suggested might be related to cyberbullying perpetration when looked at individually (things such as other risky behaviors, technology use, parental behaviors, etc.). However, when analyzed together, only one of these variables (i.e., risky behaviors) remained a statistically significant predictor of cyberbullying perpetration in high school students. Simultaneously evaluating the effects of additional and multiple variables in a middle school sample remains a ripe area for future research.

\section{Conclusions}

The negative consequences of high verbal aggression are well documented in a wide variety of contexts. This study provides further evidence regarding the importance of teaching middle school students to understand and control verbal aggression (see Infante [75] for several well-reasoned examples of how this might be conducted in a classroom setting). These and similar lessons are already part of traditional violence and cyberbullying prevention interventions, and the results from numerous studies indicate that it is possible to reduce verbal aggression and related behaviors in junior high and high school students [76-79]. Given that both verbal aggression and cyberbullying fall within the domain of communication, the field of social science is poised to play a key role in understanding and preventing these destructive behaviors.

Author Contributions: Conceptualization, J.E. and A.J.R.; methodology, J.E. and A.J.R.; formal analysis, J.E. and A.J.R.; writing-original draft preparation, J.E. and A.J.R.; writing-review and editing, J.E.; supervision, A.J.R.; project administration, A.J.R. All authors have read and agreed to the published version of the manuscript.

Funding: This research received no external funding.

Data Availability Statement: The data presented in this study are available on request from the corresponding author.

Conflicts of Interest: The authors declare no conflict of interest.

\section{References}

1. Social Media Fact Sheet. Available online: https://www.pewresearch.org/internet/fact-sheet/social-media/ (accessed on 12 August 2021).

2. Most, U.S. Teens Who Use Cellphones Do It to Pass Time, Connect with Others, Learn New Things. Available online: https: / / www.pewresearch.org/fact-tank/2019/08/23/most-u-s-teens-who-use-cellphones-do-it-to-pass-time-connect-withothers-learn-new-things / (accessed on 12 August 2021).

3. Smahel, D.; Machackova, H.; Mascheroni, G.; Dedkova, L.; Staksrud, E.; Ólafsson, K.; Livingstone, S.; Hasebrink, U. EU Kids Online 2020: Survey Results from 19 Countries. Available online: https://www.lse.ac.uk/media-and-communications/assets/ documents/research/eu-kids-online/reports/EU-Kids-Online-2020-10Feb2020.pdf (accessed on 13 August 2021).

4. Englander, E. Childhood access to technology and cyberbullying. J. Pediatrics Pediatric Med. 2019, 3, 1-4. [CrossRef]

5. Roberto, A.J.; Eden, J. Cyberbullying: Aggressive communication in the digital age. In Arguments, Aggression, and Conflict: New Directions in Theory and Research; Avtgis, T.A., Rancer, A.S., Eds.; Routledge: New York, NY, USA, 2010; pp. $198-216$.

6. Peter, I.; Petermann, F. Cyberbullying: A concept analysis of defining attributes and additional influencing factors. Comput. Hum. Behav. 2018, 86, 350-366. [CrossRef]

7. Preventing Bullying. Available online: https://www.cdc.gov/violenceprevention/pdf/yv/Bullying-factsheet_508.pdf (accessed on 12 August 2021).

8. Doumas, D.M.; Midgett, A. Witnessing cyberbullying and internalizing symptoms among middle school students. Eur. J. Investig. Health Psychol. Educ. 2020, 10, 957-966. [CrossRef]

9. Verdict in My Space Suicide Case. Available online: https:/ /www.nytimes.com/2008/11/27/us/27myspace.html (accessed on 12 August 2021).

10. Child Porn Arrests Made in Rehtaeh Parsons Cyberbullying Case. Available online: http://www.csmonitor.com/USA/Justice/ 2013/0809/Child-porn-arrests-made-in-Rehtaeh-Parsons-cyberbullying-case (accessed on 12 August 2021). 
11. Mesa Family Didn't Know 10-Year Old Girl Was Being Cyberbullies Until after She Killed Herself. Available online: https:/ / www.azcentral.com/story/news/local/mesa/2020/08/06/mesa-family-seeks-answers-after-10-year-old-girl-diessuicide/5564628002 (accessed on 12 August 2021).

12. The Family of a Teen Who Died by Suicide after Being Outed by Cyberbullies Is Demanding Justice. Available online: https://www.cnn.com/2019/09/30/us/channing-smith-suicide-cyberbullying-tennessee-trnd/index.html (accessed on 12 August 2021).

13. Camerini, A.L.; Marciano, L.; Carrara, A.; Schulz, P.J. Cyberbullying perpetration and victimization among children and adolescents: A systematic review of longitudinal studies. Telemat. Informat. 2020, 49, 101362. [CrossRef]

14. Kowalski, R.M.; Limber, S.P. Electronic bullying among middle school students. J. Adolesc. Health 2007, 41, S22-S30. [CrossRef] [PubMed]

15. Roberto, A.J.; Eden, J.; Savage, M.W.; Ramos-Salazar, L.; Deiss, D.M. Outcome evaluation results of school-based cybersafety promotion and cyberbullying prevention intervention for middle school students. Health Commun. 2014, 29, 1029-1042. [CrossRef] [PubMed]

16. Glascock, J. Contribution of verbally aggressive TV exposure and perceived reality to trait verbal aggression. Commun. Rep. 2021, 1-14. [CrossRef]

17. Roberto, A.J.; Eden, J.; Savage, M.W.; Ramos-Salazar, L.; Deiss, D.M. Prevalence and predictors of cyberbullying perpetration by high school seniors. Commun. Q. 2014, 62, 97-114. [CrossRef]

18. Liu, J.; Lewis, G.; Evans, L. Understanding aggressive behavior across the life span. J. Psychiatr. Ment. Health Nurs. 2013, 20, 156-168. [CrossRef]

19. Li, Q. New bottle but old wine: A research of cyberbullying in schools. Comput. Hum. Behav. 2007, 23, 1777-1791. [CrossRef]

20. Savage, M.; Tokunaga, R. Moving toward a theory: Testing an integrated model of cyberbullying perpetration, aggression, communication skills, and internet self-efficacy. Comput. Hum. Behav. 2017, 71, 353-361. [CrossRef]

21. Musharraf, S.; Bauman, S.; Anis-ul-Haque, M.; Malik, J. Development and validation of ICT self-efficacy scale: Exploring the relationship with cyberbullying and victimization. Int. J. Environ. Res. Public Health 2018, 15, 2867. [CrossRef] [PubMed]

22. Infante, D.A.; Wigley, C.J. Verbal aggressiveness: An interpersonal model and measure. Commun. Monogr. 1986, 53, 61-69. [CrossRef]

23. Aloia, L.S.; Solomon, D.H. The physiology of argumentative skills deficiency: Cognitive ability, emotional competence, communication responses qualities and responses to conflict. Commun. Monogr. 2015, 82, 315-338. [CrossRef]

24. Infante, D.A.; Chandler, T.A.; Rudd, J.E. Test of an argumentative skill deficiency model of interspousal violence. Commun. Monogr. 1989, 56, 163-177. [CrossRef]

25. Infante, D.A.; Sabourin, T.C.; Rudd, J.E.; Shannon, E.A. Verbal aggression in violent and nonviolent marital disputes. Commun. Q. 1990, 38, 361-371. [CrossRef]

26. Sabourin, T.C.; Infante, D.A.; Rudd, J.E. Verbal aggression in marriages: A comparison of violent, distressed but nonviolent, and nondistressed couples. Hum. Commun. Res. 1993, 20, 245-267. [CrossRef]

27. Roberto, A.J.; Carlyle, K.E.; McClure, L. Communication and corporal punishment: The relationship between parents' use of verbal and physical aggression. Commun. Res. Rep. 2006, 23, 27-33. [CrossRef]

28. Roberto, A.J.; Carlyle, K.E.; Goodall, C.E.; Castle, J.D. The relationship between parents' verbal aggressiveness and responsiveness and young adult children's attachment style and relational satisfaction with parents. J. Fam. Commun. 2009, 9, 90-106. [CrossRef]

29. Roberto, A.J. Applying the argumentative skill deficiency model of interpersonal violence to adolescent boys. Commun. Res. Rep. 1999, 16, 325-332. [CrossRef]

30. Carlyle, K.E.; Steinman, K.J. Demographic differences in the prevalence, co- occurrence, and correlates of adolescent bullying at school. J. Sch. Health 2007, 77, 623-629. [CrossRef]

31. Escortell, R.; Aparisi, D.; Martínez-Monteagudo, M.C.; Delgado, B. Personality traits and aggression as explanatory variables of cyberbullying in Spanish preadolescents. Int. J. Environ. Res. Public Health 2020, 17, 5705. [CrossRef]

32. Teng, Z.; Nie, Q.; Zhu, Z.; Guo, C. Violent video game exposure and (cyber)bullying perpetration among Chinese youth: The moderating role of trait aggression and moral identity. Comput. Hum. Behav. 2020, 104, 1-10. [CrossRef]

33. Espelage, D.L.; Hong, J.S.; Valido, A. Cyberbullying in the United States. In International Perspectives on Cyberbullying. Palgrave Studies in Cybercrime and Cybersecurity; Baldry, A., Blaya, C., Farrington, D., Eds.; Palgrave Macmillan: London, UK, 2018; pp. 65-99. [CrossRef]

34. Anderson, M. A Majority of Teens Have Experienced Some Form of Online Cyberbullying. Available online: https://www. pewresearch.org/internet/2018/09/27/a-majority-of-teens-have-experienced-some-form-of-cyberbullying/ (accessed on 12 August 2021).

35. Ortiz-Marcos, J.M.; Tomé-Fernández, M.; Fernández-Leyva, C. Cyberbullying analysis in intercultural educational environments using binary logistic regression. Future Internet 2021, 13, 15. [CrossRef]

36. Kowalski, R.; Limber, S.P.; McCord, A. A developmental approach to cyber-bullying: Prevalence and protective factors. Aggress. Violent Behav. 2018, 45, 20-32. [CrossRef]

37. Tokunaga, R.S. Following you home from school: A critical review and synthesis of research on cyberbullying victimization. Comput. Hum. Behav. 2010, 26, 277-287. [CrossRef] 
38. Hinduja, S.; Patchin, J.W. Cyberbullying: An exploratory analysis of factors related to offending and victimization. Deviant Behav. 2008, 29, 129-156. [CrossRef]

39. Williams, K.R.; Guerra, N.G. Prevalence and predictors of internet bullying. J. Adolesc. Health 2007, 41, S14-S21. [CrossRef] [PubMed]

40. Gaffney, H.; Farrington, D.P.; Espelage, D.L.; Ttofi, M.M. Are cyberbullying intervention and prevention programs effective? A systematic and meta-analyticical review. Aggress. Violent Behav. 2019, 45, 134-153. [CrossRef]

41. Yubero, S.; Navarro, R.; Elche, M.; Larrañaga, E.; Overjero, A. Cyberbullying victimization in higher education: An exploratory analysis of its associate with social and emotional factors among Spanish students. Comput. Hum. Behav. 2017, 75, 439-449. [CrossRef]

42. Padgett, J.K.; Tremblay, P.F. Gender differences in aggression. In The Wiley Encyclopedia of Personality and Individual Differences: Personality Processes and Individual Differences; Carducci, B.J., Nave, C.S., Eds.; John Wiley \& Sons, Ltd.: Hoboken, NJ, USA, 2020; Volume 3, pp. 173-177.

43. Sourander, A.; Klomek, A.B.; Ikonen, M.; Lindroos, J.; Luntamo, T.; Koskelainen, M.; Ristkari, T.; Helenius, H. Psychosocial risk factors associated with cyberbullying among adolescents: A population-based study. Arch. Gen. Psychiatry 2010, 67, 720-728. [CrossRef] [PubMed]

44. Ybarra, M.L.; Mitchell, K.J. Online aggressor/targets, aggressors, and targets: A comparison of associated youth characteristics. J. Child. Psychol. Psychiatry 2004, 45, 1308-1316. [CrossRef]

45. Brody, N.; Vangelisti, A.L. Cyberbullying: Topics, strategies, and sex differences. Comput. Hum. Behav. 2017, 75, 739-748. [CrossRef]

46. Bartlett, C.; Coyne, S.M. A meta-analysis of sex differences in cyberbullying behavior: The moderating role of age. Aggress. Behav. 2014, 40, 474-488. [CrossRef]

47. Olweus, D. Olweus Bullying Questionnaire; Hazelden Betty Ford Foundation: Hazelden, MN, USA, 2007.

48. Roberto, A.J.; Finucane, M. The assessment of argumentativeness and verbal aggressiveness in adolescent populations. Commun. Q. 1997, 45, 21-36. [CrossRef]

49. Levine, T.R.; Beatty, M.J.; Limon, S.; Hamilton, M.A.; Buck, R.; Chory-Assad, R.M. The dimensionality of the verbal aggressiveness scale. Commun. Monogr. 2004, 71, 245-268. [CrossRef]

50. Infante, D.A.; Gorden, W.I. Argumentativeness and affirming communicator style as predictors of satisfaction/dissatisfaction with subordinates. Commun. Q. 1989, 37, 81-90. [CrossRef]

51. Cohen, J. Statistical Power Analysis for the Behavioral Sciences, 2nd ed.; Academic Press: New York, NY, USA, 1988.

52. Bettencourt, B.A.; Miller, N. Gender differences in aggression as a function of provocation: A meta-analysis. Psychol. Bull. 1996, 119, 422-447. [CrossRef]

53. Archer, J. Sex differences in aggression in real-world settings: A meta-analytic review. Rev. Gen. Psychol. 2004, 8, 291-322. [CrossRef]

54. Levine, T.R.; Kotowski, M.R.; Beatty, M.J.; Van Kelegom, M.J. A meta-analysis of trait-behavior correlations in argumentativeness and verbal aggression. J. Lang. Soc. Psychol. 2012, 31, 95-111. [CrossRef]

55. Lozano-Blasco, R.; Cortés-Pascual, A.; Latorre-Martínez, M.P. Being a cyber victim and a cyberbully-The duality of cyberbullying: A meta-analysis. Comput. Hum. Behav. 2020, 111, 106444. [CrossRef]

56. Guo, S. A meta-analysis of the predictors of cyberbullying perpetration and victimization. Psychol. Sch. 2016, 53, 432-453. [CrossRef]

57. Hua, T.K.; Hwa, N.S.H.; Chong, S.T. Cyberbullying victimization and cyberbullying perpetration with self-esteem as the moderator. Int. J. Recent Technol. Eng. 2019, 8, 88-92.

58. Facts about Bullying. Available online: https://www.stopbullying.gov/resources/facts (accessed on 17 August 2021).

59. Eyuboglu, M.; Eyuboglu, D.; Pala, S.C.; Oktar, D.; Demirtaş, Z.; Arslantaş, D.; Unsal, A. Traditional school bullying and cyberbullying: Prevalence, the effect on mental health problems and self-harm behavior. Psychiatry Res. 2021, $297,113730$. [CrossRef]

60. Fisher, B.W.; Gardella, J.H.; Teurbe-Tolon, A.R. Peer cybervictimization among adolescents and the associated internalizing and externalizing problems: A meta-analysis. J. Youth Adolesc. 2016, 45, 1727-1743. [CrossRef] [PubMed]

61. Yang, C.; Chen, C.; Lin, X.; Chan, M. School-wide social emotional learning and cyberbullying victimization among middle and high school students: Moderating role of school climate. Sch. Psychol. 2021, 36, 75-85. [CrossRef]

62. Lifetime Cyber Bullying Offending Rate among Middle and High School Students in the United States from May 2007 to April 2019. Available online: https://www.statista.com/statistics/509349/student-cyber-bullying-offending-rate-usa/ (accessed on 17 August 2021).

63. Bacher-Hicks, A.; Goodman, J.; Green, J.G.; Holt, M.K. The COVID-19 Pandemic Disrupted School Bullying and Cyberbullying. Available online: https://www.edworkingpapers.com/sites/default/ files/ai21-436.pdf (accessed on 17 August 2021).

64. Vaillancourt, T.; Brittain, H.; Krygsman, A.; Farrell, A.H.; Landon, S.; Pepler, D. School bullying before and during COVID-19: Results from a population-based randomized design. Aggress. Behav. 2021, 47, 557-569. [CrossRef]

65. Cyberbullying: Dealing with Online Meanness, Cruelty, and Threats. Available online: http://mediasmarts.ca/sites/ mediasmarts/files/pdfs/publication-report/summary/YCWWIII_Cyberbullying_ExecutiveSummary.pdf (accessed on 17 August 2021). 
66. Bilsbury, T. A Systematic Review of the Prevalence of Cyberbullying in Canada. Available online: https://dalspace.library. dal.ca/bitstream/handle/10222/58197/Bilsbury-Tanya-MSc-CH\&E-July-2015.pdf?sequence=3\&isAllowed=y (accessed on 17 August 2021).

67. Calvete, E.; Orue, I.; Estévez, A.; Villardón, L.; Padilla, P. Cyberbullying in adolescents: Modalities and aggressors' profile. Comput. Hum. Behav. 2010, 26, 1128-1135. [CrossRef]

68. Polanin, J.R.; Espelage, D.L.; Grotpeter, J.K.; Ingram, K.; Michaelson, L.; Spinney, E.; Valido, A.; El Sheikh, A.; Torgal, C.; Robinson, L. A systematic review and meta-analysis of interventions to decrease cyberbullying perpetration and victimization. Prev. Sci. 2021, 1-16. [CrossRef]

69. Bilewicz, M.; Tempska, P.; Leliwa, G.; Dowgiałło, M.; Tańska, M.; Urbaniak, R.; Wroczyński, M. Artificial intelligence against hate: Intervention reducing verbal aggression in the social network environment. Aggress. Behav. 2021, 47, 260-266. [CrossRef] [PubMed]

70. Tintori, A.; Ciancimino, G.; Giovanelli, G.; Cerbara, L. Bullying and cyberbullying among Italian adolescents: The influence of psychosocial factors on violent behaviours. Int. J. Environ. Res. Public Health 2021, 18, 1558. [CrossRef] [PubMed]

71. Perren, S.; Gutzwiller-Helfenfinger, E. Cyberbullying and traditional bullying in adolescence: Differential roles of moral disengagement, moral emotions, and moral values. Eur. J. Dev. Psychol. 2012, 9, 195-209. [CrossRef]

72. Willard, N. Cyber-Safe. Kids, Cyber-Savoy Teens: Helping Young People Learn to Use the Internet Safely and Responsibly; Jossey-Bass: Hoboken, NJ, USA, 2007.

73. Schultze-Krumbholz, A.; Hess, M.; Pfetsch, J.; Scheithauer, H. Who is involved in cyberbullying? Latent class analysis of cyberbullying roles and their associations with aggression, self-esteem, and empathy. Cyberpsychol. J. Psychosoc. Res. Cyberspace 2018, 12. [CrossRef]

74. Roch, C.H.; Elsayed, M.A.; Edwards, J. Students' and parents' perceptions of disciplinary policy: Does symbolic representation matter? Am. Rev. Public Adm. 2017, 48, 329-345. [CrossRef]

75. Infante, D.A. Teaching students to understand and control verbal aggression. Commun. Educ. 1995, 44, 51-63. [CrossRef]

76. Evers, K.E.; Prochaska, J.O.; Van Marter, D.F.; Johnson, J.L.; Prochaska, J.M. Transtheoretical-based bullying prevention effectiveness trials in middle schools and high schools. Educ. Res. 2007, 49, 397-414. [CrossRef]

77. Roberto, A.J.; Zimmerman, R.S.; Carlyle, K.E.; Abner, E.L. A computer-based approach to preventing pregnancy, STD, and HIV in rural adolescents. Health Commun. 2007, 12, 53-76. [CrossRef]

78. Rancer, A.S.; Avtgis, T.A.; Kosberg, R.L.; Whitecap, V.G. A longitudinal assessment of trait argumentativeness and verbal aggressiveness between seventh and eighth grades. Commun. Educ. 2000, 49, 114-119. [CrossRef]

79. Rancer, A.S.; Whitecap, V.G.; Kosberg, R.L.; Avtgis, T.A. Testing the efficacy of a communication training program to increase argumentativeness and argumentative behavior in adolescents. Commun. Educ. 1997, 46, 273-286. [CrossRef] 